The research program of the Center for Economic Studies (CES) produces a wide range of theoretical and empirical economic analyses that serve to improve the statistical programs of the U.S. Bureau of the Census. Many of these analyses take the form of CES research papers. The papers are intended to make the results of CES research available to economists and other interested parties in order to encourage discussion and obtain suggestions for revision before publication. The papers are unofficial and have not undergone the review accorded official census Bureau publications. The opinions and conclusions expressed in the papers are those of the authors and do not necessarily represent those of the U.S. Bureau of the Census. Republication in whole or part must be cleared with the authors.

TRACING THE SOURCES OF LOCAL EXTERNAL ECONOMIES

by

Edward J. Feser*

University of North Carolina at Chapel Hill

CES 04-13 August, 2004

All papers are screened to ensure that they do not disclose confidential information. Persons who wish to obtain a copy of the paper, submit comments about the paper, or obtain general information about the series should contact Sang $V$. Nguyen, Editor, Discussion Papers, Center for Economic Studies, Washington Plaza II, Room 206, Bureau of the Census, Washington, DC 20233-6300, (301-763-1882) or INTERNET address snguyen@ces.census.gov. 
Tracing the sources of local external economies

Edward J. Feser Assistant Professor University of North Carolina CB 3140, New East Building Chapel Hill, NC 27599-3140

Voice: 919.962 .4768

Fax: 919.962.5206

E-Mail: feser@email.unc.edu

January 2002 


\section{Tracing the sources of local external economies}

Summary. In a cross-sectional establishment-level analysis using confidential secondary data, I evaluate the influence of commonly postulated sources of localized external economies-supplier access, labor pools, and knowledge spillovers-on the productivity of two U.S. manufacturing sectors (farm and garden machinery and measuring and controlling devices). Measures incorporating different distance decay specifications provide evidence of the spatial extent of the various externality sources. Chinitz's (1961) hypothesis of the link between local industrial organization and agglomeration economies is also investigated. The results show evidence of labor pooling economies and university-linked knowledge spillovers in the case of the higher technology measuring and controlling devices sector, while access to input supplies and location near centers of applied innovation positively influence efficiency in the farm and garden machinery industry. Both sectors benefit from proximity to producer services, though primarily at a regional rather than highly localized scale. 


\section{Tracing the sources of local external economies ${ }^{1}$}

\section{Introduction}

The notion of local external economies enjoyed by co-located businesses is the subject of much current writing on endogenous growth theory, new trade theory, industrial districts, and industry clusters (see Enright, 1995 and Feser, 1998, for recent reviews). Unfortunately, empirical research has not kept pace with theorizing. On the one hand are many studies of agglomeration economies that utilize industry or urban size as surrogates for local external effects (Moomaw, 1983). While such studies demonstrate a link between urban or industry scale and industrial productivity, they cannot explain what is behind the observed scale effects. Agglomeration theorists offer a variety of plausible ex post explanations for agglomeration economies, from the availability of local inputs, specialized workers, equipment, and repair facilities, to joint showrooms and advanced infrastructure (Hoover, 1937; Isard, 1956; Evans, 1972; Carlino, 1978). But, with the partial exception of Sasaki (1985), such factors are almost never directly examined in empirical work.

On the other hand is research that focuses on single sources of externalities, mainly localized knowledge spillovers derived from academic research (Jaffe, 1989; Acs, Audretsch and Feldman, 1992; Jaffe, Trajtenberg and Henderson, 1993; Adams and Jaffe, 1996; Anselin, Varga and Acs, 1997; Zucker, Darby and Armstrong, 1998). Yet comparisons of knowledge spillovers against other possible sources such as labor pools and supplier access have not been carried out, even though the sectors driving a great many local economies are not especially knowledgeintensive.

This paper addresses this major shortcoming in the extant empirical literature on 
agglomeration and spillovers by directly modeling the relationship between manufacturing productivity and a set of commonly postulated sources of spatial external economies. The methodology is a cross-sectional, micro-level production function with distance-weighted measures of interfirm proximity as technology parameters. The proximity measures are designed to assess the relative contribution to manufacturing productivity of factors such as access to research universities, the availability of an extensive labor pool, and proximity to suppliers. External economies are evidenced by statistically significant output elasticities associated with each proximity factor. The approach surmounts several common methodological problems by supplementing confidential enterprise-level data from the U.S. Bureau of the Census' Longitudinal Research Database (LRD) with detailed geographically referenced employment, research and development, and patent data for all counties of the contiguous U.S. The model is estimated and compared for two U.S. manufacturing industries of differing technology-intensity: measuring and controlling devices (SIC 382) and farm and garden machinery (SIC 352).

A justification for the choice of study industries is in order. Much research on agglomeration economies is conducted for aggregate industries, such as manufacturing as a whole or selected major sectors (e.g., two-digit SIC industries). The focus on aggregate industries may be acceptable when the concern is with the role of urban and industry size on productivity (though see Moomaw, 1998). However, disentangling the influence of various sources of agglomeration economies requires the analysis of more narrowly defined sectors for which valid and defensible measures of specialized suppliers, labor pools, and knowledge spillovers can be developed. In the present case, resource and data constraints precluded the analysis of multiple detailed sectors. Consequently, two sectors were selected for analysis and comparison based on their differing knowledge- or technology-intensity. Measuring and 
controlling devices is a key high-technology intermediate supplier to a number of high technology industries, including aerospace, search and navigation equipment, and missiles and space vehicles, as well as moderate-technology sectors such as appliances. In contrast, farm and garden machinery is a final market, largely producer durable industry with a range of comparatively standardized products. Though obviously tentative, comparison of the findings for the two industries provides important hints as to the differential influence of input supplies, labor pools, and knowledge spillovers on high tech versus traditional industries.

\section{Modeling Externalities and Productivity}

In the empirical agglomeration economies literature, external economies associated with urban or industry scale are conceptualized as technology shifters of the conventional production function:

$$
Y_{i}=g\left(A_{i}\right) f\left(L_{i}\right)
$$

where $f\left(L_{i}\right)$ describes production factors internal to the firm and $g\left(A_{i}\right)$ denotes external influences on production associated with industry or urban scale (Moomaw, 1983). Following Weber (1929) and Hoover (1937), if $A_{i}$ is industry size (e.g., employment or output), the economies are dubbed localization economies. If $A_{i}$ is urban size (e.g., population), they are called urbanization economies. A considerable literature focuses on whether industry scale or population scale is the more appropriate surrogate of underlying agglomeration effects (Nakamura, 1985; Henderson, 1986; Moomaw, 1988).

In essence, the objective of this paper is to specify the arguments of $g(\cdot)$ in a way that better captures the specific sources of productivity gains attributable to the spatial concentration 
of firms and other supporting organizations. Obviously the number of such sources could be quite large and easily exceed available degrees of freedom. Therefore, the focus here is on those factors that have received the bulk of attention in the recent literature, specifically Marshall's ([1890], 1961) three principal advantages of industrial district locations: access to specialized suppliers (of both intermediate goods and producer services), pools of workers with specialized skills, and knowledge spillovers (see also Krugman, 1991).

With respect to input supply, agglomeration theorists cite three reasons why a firm located nearby supplier industries is likely to be more efficient than more isolated producers. First, the need for such firms to produce its inputs in-house (and at higher cost) is reduced if the local market is sufficient to support specialized contract suppliers that serve multiple producers; in this context, the spatial economy is essentially a type of "external factor" that serves a substitute for internal factors (Marshall, 1961; Stigler, 1951; Scott, 1986). Second, physical proximity to input supplies permits greater flexibility in that inputs can be more easily obtained in smaller quantities or on an as-needed basis (e.g., as in a just-in-time delivery system). Scott (1986) and Goe (1991) suggest that proximity to suppliers is especially critical for firms in markets with volatile levels of demand. Even if a plant normally purchases its supplies or services from more distant regions, it could still conceivably benefit from local sources of supply in the event of an unanticipated interruption of its normal supplies or when its usual suppliers cannot meet necessary levels of demand. Third, buyers can more easily work directly with their suppliers when the latter are located nearby. Tight contractual agreements between original equipment manufacturers (OEMs) and their suppliers often include direct collaborative arrangements between the design teams of both parties that are best implemented in joint locations (Burt, 1989; Newman, 1989; Imrie and Morris, 1992; Klier, 1994; Helper, 1991). 
Access to deep pools of labor is perhaps the most commonly cited and least empirically studied source of spatial economies. Greater availability of skilled, experienced labor grants firms substantial flexibility to expand and contract with minimal disruption (Krugman, 1991). Where a supply of trained workers is reasonably assured, firms have greater scope for responding to shifts in product demand, allowing them to maintain a higher level of efficiency through continual adjustments in their input mixes. In addition, in a region where a large number of producers in related industries employ workers with similar skills (e.g., an industrial complex), the overall average level of worker skill (or quality) may be improved. According to Marshall (1961), the dominance of a given industry (or complex of industries) in a place can lead to a particular culture of expertise not only of the producers, but also of the workers they employ. Knowledge spillovers, the third of Marshall's key external economies, have received considerable attention of late in the new growth theory and industrial districts literatures. Using Robinson's (1931) dichotomy, knowledge spillovers are actually of two varieties: mobile and immobile. The concept of mobile knowledge spillovers captures the generalized technological progress that occurs over time and effectively at a global scale; such spillovers may represent embodied or disembodied technical change as conceived in the growth literature. Some innovations, learning, and technological discoveries will be of a nature that they impact industry everywhere, or they may diffuse rapidly enough to assume they are mobile over any given study period. Non-localized spillovers that are best captured by the exogenous technical change parameter in the traditional growth model (Lucas, 1988). In the cross-sectional framework employed in this study, mobile spillovers are essentially held constant and the focus is on assessing the capacity of different firms to capture localized, efficiency-enhancing knowledge. Immobile or localized knowledge spillovers are knowledge transfers that do not diffuse 
rapidly over space, perhaps because of their tacit or uncodified nature. Localized knowledge spillovers are likely to be strongest in regions with high rates of innovation and knowledge creation. Plants located in the midst of such innovative regions are likely to more productive as they learn more quickly from neighboring manufacturers and appropriate external effects from private and public research and development activities (Cooke and Morgan, 1998; Cooke, Boekholt and Tödtling, 2000).

From theory to measurement. The researcher interested in empirically testing the relative contribution of localized input supplies, labor pools, and knowledge spillovers to productivity immediately faces three major challenges: first, the selection of the unit of analysis (the region or establishment); second, the specification of the production function and construction of appropriate factor input and output measures; and third, the development of construct-valid indicators of the externality concepts themselves. Most existing studies utilize regional-level production functions for which published output and factor data are readily available. But such an approach necessitates the use of crude regional-level proxies for external economies, most commonly measures of urban and industry size. In contrast, I adopt the individual business establishment as the unit of analysis, employ a micro-level production function estimated with confidential U.S. Census of Manufactures data, and develop locationand establishment-specific measures of externality concepts.

The micro level approach to studying the influence of externalities and spillovers on productive efficiency has distinct advantages. Spatial proximity measures may be modeled and interpreted as determinants of productive efficiency of the individual enterprise. With sufficient data on the characteristics of the study establishment's location, variables may be constructed so that enterprises in different locations-even within the same metropolitan area-face different 
mixes or intensities of hypothesized external influences. In effect, a micro level framework permits the assessment of local externality effects at the most appropriate spatial scale, that of the immediate area surrounding the enterprise's site. The approach also lends itself to the inclusion of important control variables. In the present case, one important but often neglected control derives from Chinitz's (1961) hypothesis of the link between industrial structure and agglomeration.

Specifically, I use the transcendental logarithmic function to implement equation (1):

$$
\begin{aligned}
\ln Y & =\alpha_{0}+\sum_{i} \alpha_{i} \ln X_{i}+\sum_{m} \xi_{m} \ln A_{m}+\frac{1}{2} \sum_{i} \sum_{j} \beta_{i j} \ln X_{i} \ln X_{j} \\
& +\frac{1}{2} \sum_{m} \sum_{n} \gamma_{m n} \ln A_{m} \ln A_{n}+\sum_{i} \sum_{m} \delta_{i m} \ln X_{i} \ln A_{m}
\end{aligned}
$$

where $X$ and $\mathrm{A}$ index factor inputs and sources of externalities, respectively. I estimate the production function jointly with a set of cost share equations utilizing the inverse input demand framework outlined by Kim (1992). The cost share equations for $i$ conventional inputs are written:

$$
S_{i}=\frac{\alpha_{i}+\sum_{j} \beta_{i j} \ln X_{j}+\sum_{m} \delta_{i m} \ln A_{m}}{\sum_{i} \alpha_{i}+\sum_{i} \sum_{j} \beta_{i j} \ln X_{j}+\sum_{i} \sum_{m} \delta_{i m} \ln A_{m}}
$$

while the role of a given proximity factor as a source of externalities is revealed by:

$$
\frac{\partial \ln Y}{\partial \ln A_{m}}=\xi_{m}+\sum_{i} \delta_{i m} \ln X_{i}+\sum_{n} \gamma_{m n} \ln A_{n}
$$

Equation (4) gives the percent change in output $Y$ with respect to a one percent change in proximity index $A_{m}$, holding all inputs and other proximity measures constant.

The translog is attractive because it imposes the fewest technical assumptions of other popular functional forms. Kim's (1992) framework has the additional advantage of avoiding $a$ 
priori restrictions (e.g., homotheticity or homogeneity) that are a feature of translog applications that estimate the cost function or associated factor-share (input demand) functions. In the interest of conserving space, readers are referred to Feser (2001a) for a detailed discussion of the usefulness of Kim's methodology in the context of the study of agglomeration economies. The following section describes the specific measures and sources of data used to implement the system in equations (2) and (3).

\section{Variables and Data}

The translog production function and cost share equations are estimated for the two study industries for 1992, the most recent year for which all necessary data sources could be assembled under consistent industrial classification systems. The production function includes four conventional inputs $K, L, E, M$ (capital, labor, energy, and materials). The measures for the inputs, along with measures for output $(Y)$ and cost shares $\left(S_{i}\right)$ are constructed with data from the Longitudinal Research Database (LRD) of the U.S. Bureau of the Census. The LRD contains the microdata from the Census and Annual Surveys of Manufactures, among other governmentsponsored surveys. The appendix describes the specific measurement of the conventional factors in the production function. The current section focuses on the measurement of the spatial proximity variables.

Supplier Access. I utilize a generalization of the agglomeration potential concept of Richardson (1974) to measure the availability of local inputs and producer services. Each plant $i$ in industry $k$ purchases intermediate inputs from $p(p, \ldots, q)$ industries with plants located at points $j$. The proportion of total intermediate input purchases by plant $i$ in industry $k$ from each supplier industry $p$ is given by $r_{k p}$. Then, a measure of total potential intermediate input supply 
in the region surrounding plant $i\left({ }_{A t, i}\right)$ that accounts for the distance between plant $i$ and supply sources, the size of sources of supply, and the relative mix of inputs available to plant $i$, is given by the index:

$$
A_{t, i}=\sum_{p} \sum_{j} E_{p, j} h_{i j} r_{k p}
$$

where $E_{p, j}$ is a measure of the size of industry $p$ at point $j$ (e.g., employment, estimated output, or number of establishments). The factor $h_{i j}$ is the distance between plant $i$ and sources $j$ specified in a generalized form:

$$
h_{i j}=\left(m-d_{i j}\right) /\left(m-\alpha d_{i j}\right)
$$

where $m$ is the maximum allowable distance and alpha is a decay parameter. As $\alpha$ approaches minus infinity, $h_{i j}$ resembles the simple inverse of distance. Note that equation (5) assumes that a given plant in industry $k$ purchases the same relative mix of inputs as the average within its industry. A measure of producer services availability, $A_{s, i}$, may be derived analogously, where the $E_{p, j}$ refer to size measures at points $j$ for $p$ producer services sectors.

In addition to spatially and industrially disaggregated data on industry size, the implementation of equation (5) requires an appropriate distance measure and an assumption about the form of decay over some relevant distance. The ratio of individual inputs to total inputs for each industry, $r_{k p}$, is from the Benchmark Input-Output Accounts of the United States, while the identification of producer services sectors was based on the classification in Beyers (1992). The primary measure of size $\left(E_{p, j}\right)$, where $j$ is the county centroid, is employment as reported in the 1992 County Business Patterns (CBP). Where employment information is suppressed in CBP, the reported data on the number of plants in specific size categories were 
used to construct estimates by assuming the category's midpoint employment for each establishment.

In equation (6), the $d_{i j}$ are great circle arc distances between counties (each plant is assumed located at its county's population centroid) and the parameter $m$ is set at fifty miles since transportation studies have shown that very little commuting occurs beyond that distance. The variables are initially constructed by setting $\alpha$ equal to 0.75 , which simply represents one plausible specification of the differential intensity of interaction likely among neighboring firms. It is drawn in Figure 1 along with three additional alternatives. A common default in studies of spatial interaction is the simple inverse of distance (approximated by setting alpha equal to an arbitrarily high number). The inverse is an extreme decay that has the practical effect of reducing the proximity measures to county-level indicators since any values for neighboring counties are heavily discounted.

[Figure 1 near here]

One could view the specification of the form of the distance decay as essentially arbitrary. However, introducing alternative decay profiles and observing the effects on the estimated production function generates unique information regarding the spatial characteristics of particular externality sources. For example, the results suggest that the productivity effects of proximity to producer services decays gradually. That is, I find that for both study sectors, the elasticity of proximity to producer services is declines as alpha falls from 0.75 to -0.50 . One interpretation is that the benefits of access to producer services are region-wide in their spatial extent; the enterprise need not locate immediately nearby by such producer services suppliers, though location in a producer services-rich region is advantageous. Such a result is certainly consistent with the predominant pattern of urban spatial structure in the U.S., with producer 
services occupying the urban center and manufacturers seeking green field, or at least, suburban locations with sufficient land and good highway access. The findings for other proximity measures also vary as alternative decays are introduced.

SIC 382: Proximity to Manufacturing Demand. The measuring and controlling devices industry is itself a key supplier to a wide range of final market manufacturing industries, from aerospace (aircraft, missiles, and space vehicles) to industrial and home appliances (refrigeration and heating equipment, electric housewares and fans, and household refrigerators and freezers). Just as manufacturers may derive benefits from proximate location to their own suppliers, they may also benefit from proximity to their major customers. I test that conjecture by including a demand-side proximity variable for plant $i$ in SIC 382, $A_{d, i}$, that is constructed in a similar fashion to the intermediate input and producer services supply variables.

Specialized Labor Pool. Alfred Marshall's famous statement regarding the "mysteries in the air" in the industrial district was made with direct reference to the important role of a geographic concentration of worker skills in a heavily localized industry. The mysteries of industry "become no mysteries; but are as it were in the air, and children learn many of them unconsciously (1961, p. 271).” Mutual learning takes place through a concentration of workers engaged in similar tasks. In many respects, Marshall's labor pool is consistent with Hoover's localization economy: both proximity and specialization are important dimensions of the two concepts. However, the localization economy as typically measured ignores the fact that many industries are engaged in similar and related manufacturing and are therefore using and exchanging workers with similar skills and experience. Those similarities with respect to workforce requirements are analogous to similarities in technology that are often used to identify buyer-supplier chains and industrial complexes. 
In order to construct a labor pool variable that measures the specialized skill base of each study plant's location, national 3-digit SIC industries were first grouped into clusters based on similarities in occupational staffing patterns. The approach assumes that detailed occupation is a reasonable proxy indicator for skill characteristics. Each column in Bureau of Labor Statistics' industry-occupation matrix (from the Occupational Employment Survey) constitutes the labor requirements vector-in terms of detailed occupation-for a specific manufacturing sector. Factor analysis of the matrix reduced the number of columns (or variables) to twenty-four principal components, or a set of mutually exclusive groups of industries that may be interpreted as sharing similar labor force requirements. The farm and garden machinery industry is clustered with nineteen other sectors, including, among others, miscellaneous fabricated metals, household appliances, motor vehicles and equipment, and cutlery and hardware. Measuring and controlling devices is joined with five other industries: computer and office equipment, aircraft and parts, guided missiles and space vehicles, search and navigation equipment, and photographic equipment and supplies.

Given $p$ cluster industries, a measure of labor specialization in the 50 mile shed surrounding plant $i$ in a given study industry is defined as:

$$
A_{r, i}=\frac{\sum_{p} \sum_{j} \frac{E_{p j} / E_{j, m}}{E_{p} / E_{m}}}{\sum_{j} h_{i j}}, \quad h_{i j}=1 \text { if } d_{i j} \leq 50, \text { otherwise } h_{i j}=0
$$

where $E_{p j}$ is employment in industry $p$ at location $j, E_{j, m}$ is total manufacturing employment at location $j, E_{p}$ is U.S. employment in industry $p, E_{m}$ is total U.S. manufacturing employment, and $h_{i j}$ is a zero-one indicator variable based on the distance, $d_{i j}$, between county centroids. Equation (7) measures the degree to which plant locations are specialized in a particular cluster's 
industries. Where that specialization is greatest is where cluster members are likely to enjoy the most significant labor pooling economies. Since the variable does not account for regional differences in educational quality, the share of the population 25 years old and older with some college education in plant $i$ 's commuting shed is included in the model as well (labeled ATTAIN and derived from the 1990 Census of Population).

Localized Knowledge Spillovers. Attempts to measure the influence of knowledge externalities have focused on identifying conditions under which they are likely to be strongest, such that the conditions themselves become proxy variables. For example, Glaeser et al. (1992) interpret Romer (1986) as predicting that knowledge externalities will be most significant among firms in the same industry. The implied corollary is that industries that represent a high level of employment in a given city relative to that industry nationally will grow faster as they benefit from information externalities; i.e a location quotient in a metropolitan-level growth equation becomes the indicator of spillovers. This study adopts a similar approach, except that the corollaries to the general theory of spillovers are more direct. Spillovers are expected to be most prevalent in locations with high rates of public and private sector innovation. A public sector innovation rate for plant $i$ 's location is defined as:

$$
A_{u, i}=\sum_{j} U_{j} h_{i j}
$$

where $U_{j}$ is total research expenditures by universities in location (county) $j$ and $h_{i j}$ is distance between the locations (counties) $i$ and $j$, specified in the generalized decay form. Data for $U_{j}$ are from the National Science Foundation's 1993 Survey of Scientific and Engineering Expenditures at Universities and Colleges. ${ }^{2} \mathrm{R} \& \mathrm{D}$ funds are included only for those disciplines most relevant to the study industries. For farm and garden machinery, the relevant disciplines are mechanical 
engineering, industrial engineering, electrical engineering, other engineering, other physical sciences, and agricultural sciences. For the measuring and controlling devices sector, relevant disciplines are aerospace engineering, electrical engineering, mechanical engineering, industrial engineering, other engineering, astronomy, physics, other physical sciences, and computer science.

The degree of private sector innovative activity at plant $i$ 's location, $A_{P, i}$ is measured by the number of utility patents granted to residents, per capita, in the plant's 50 mile shed. Patent grants by county are from the U.S. Patent and Trademark Office. Though patent data are not without limitations (see Griliches, 1990), the county-based utility patent measure represents an improvement over alternatives (such as employment in high technology sectors or state-level private sector research and development expenditures) as a broad indicator of real inventive activity in particular localities.

Key Controls. Two key controls are urban diseconomies and local industry structure. A potentially important indirect influence on spatial externalities and agglomeration economies is industry structure. With regard to diseconomies, the analysis focuses on positive spatial externalities since aggregate size proxies (such as population) are not being used to evaluate the proximity effect. While some researchers view population size as an indicator of diseconomies, other studies have found positive economies associated with population. Here the primary concern is with ensuring that the proximity indicators do not indirectly measure generalized disadvantages associated with dense, urban places. Therefore, a population density variable is included to control for possible congestion effects and other urban diseconomies. The variable, DENSITY, is defined as the number of persons per square mile in plant $i$ 's 50 mile shed. Population for each county is from the Bureau of Economic Analysis. 
The local industry structure control is derived from the seminal paper by Chinitz in 1961 which attempted to draw attention away from the near-exclusive focus on city and industry size as the primary drivers of agglomeration economies. Chinitz called for "the specification of a function which relates external economies and diseconomies to industry structure, size being held constant (p. 289)." In particular, he pointed toward the need to assess the degree to which industry across regions is competitively organized, meaning "more entrepreneurs per dollar of output than an industry which is organized along oligopolistic lines (p. 284)." He viewed oligopolistic regional environments as less likely to both "breed" entrepreneurs and to support those that in-migrate.

Furthermore, Chinitz suggested that externalities are likely to be less prevalent where industry is organized along oligopolistic lines. Although a region's dominant industries are largely responsible for the quantity and variety of manufactured inputs and services in a place, they can also influence how other firms and industries take advantage of such inputs and services. Highly innovative firms can limit localized knowledge spillovers if they operate in a secretive or insular fashion, a point echoed by Saxenian (1994) in her comparison of high technology industry in Silicon Vallen and Boston's Route 128 (see also Norton 2000). Chinitz's comments are also consistent with research on the changing nature of buyer-supplier relations that posits that contracting agreements that serve to bind buyers and suppliers closely together are becoming increasingly common, such that suppliers serve only a few major customers. Even the presence of a deep supplier chain in a place is no guarantee that a given firm, particularly a small one, will be able to secure local sources of key inputs.

To operationalize Chinitz's hypothesis, the competitive organization of industry in location (county) $i$ is measured by $C R A T I O$, the share of total manufacturing sales made by the 
four largest firms in the zone of commutation in which the location (county) falls. Computing resource constraints precluded the calculation of $C R A T I O$ for each plant's 50 mile shed. Commuting zones, developed by the Economic Research Service of the U.S. Department of Agriculture using Census journey-to-work data, are mutually exclusive groups of counties that cover all fifty states (741 zones in total for 1990). Commuting zones have the advantage of representing one of the most rigorous regional definitions available, and, unlike metropolitan areas, encompass all counties in the U.S.

\section{Basic Descriptives}

Table 1 reports means and standard deviations of the model variables for each industry. The final sample sizes of 863 and 2,609 for SICs 352 and 382, respectively, are a result of eliminating records in the LRD that are developed from imputed data. In some circumstances, the use of records with imputed data is appropriate. However, since the translog production function is highly sensitive to the quality of the underlying data, such records were excluded from the study, reducing the sample sizes for each industry by roughly 50 percent. Because imputed data records (administrative records in Census terminology) tend to be very small plants (typically employing fewer than 3 workers), the samples are not representative of the smallest producers in each study industries.

[Tables 1 and 2 near here]

Pairwise correlations among the externality and spillover indicators are reported in Table 2. There are two things to note. First, for both study sectors, most of the correlations are positive, as is consistent with the underlying theory. Second, none of the correlations are excessively high, which suggests that not only does each factor measure a different concept, but 
the potential for excessive multicollinearity in the estimated model is not as extreme as might be expected given the variables' similar construction.

[Table 3 near here]

Which proximity measures are associated mainly with population scale (and thus urbanization effects) versus industry scale (localization effects)? Interestingly, Table 3 indicates that the usual proxies for agglomeration economies-industry and urban size-are not uniformly associated with specific sources of economies, at least for the two study industries considered here. The table reports pairwise correlations between the externality factors and population and study industry employment in plant $i$ 's 50 mile shed. In the case of the farm and garden machinery industry, population represents a better indicator of four out of five of the proximity variables, including local input supply, producer services, per capita patents, and university R\&D. Industry employment is more highly correlated with specialized labor pools. For SIC 382, industry size is more highly correlated than population with the following factors: input supply, specialized labor pools, local patenting rates, and university R\&D. For both sectors, population is the best indicator of proximity to specialized producer services. In general, Table 3 suggests that is very difficult to infer anything about the underlying dynamics driving agglomeration economies based on analyses of the link between population/industry scale and productivity. That is, indeed, the justification for disentangling sources of externalities directly.

\section{Model Results}

To generate a final, revised set of parameter estimates, I utilized a multi-stage modeling process that 1) estimated the production function and cost shares for each industry including all proximity factors and controls (via iterated seemingly unrelated regressions); 2) dropped 
insignificant controls and cross-terms on the proximity factors (following likelihood ratio tests for factor augmentation and Hicks-neutrality of specific proximity indicators); and 3) reestimated the model repeatedly under nested assumptions of homotheticity, homogeneity, and constant returns to scale. Few of the technology cross terms ( $\gamma_{m n}$ in generalized equation 2$)$ were significant for either study sector at conventional levels; the hypothesis that the terms are all jointly equal to zero could not be rejected for either industry. A second model with the cross terms eliminated indicated that some proximity effects are factor augmenting while others are Hicks-neutral. In particular, for the farm and garden machinery sector, there is evidence that services and the local innovation rate (patents per capita) enter the production function in factor augmenting form. For SIC 382, the factor augmenting externality effects appear to be university R\&D, patent rates, and specialized labor pools. Homogeneity proved to be the most appropriate restriction. The results of all likelihood ratio tests are reported in Table $4 .^{3}$

\section{[Table 4 near here]}

The forms of the final estimated production functions for the two sectors are provided in the Appendix. Note that the models were tested and revised with the distance decay parameter in the various proximity variables specified as $\alpha=0.75$ (from equation 6). Once the final forms of the production functions were determined, the systems were re-estimated with the variables constructed with the three alternative distance decays. The final parameter estimates and asymptotic standard errors are reported in Table 5.

Consider first the control variables. While the competitive organization variable, CRATIO, was eliminated in early stage models for SIC 352 (it was highly insignificant in all rounds of estimation), it appears to be a key productivity determinant in the measuring and controlling devices sector. Offering probably the strongest evidence in favor of the Chinitz 
hypothesis to date, each doubling of the four-firm concentration ratio is associated with a 13.1 percent reduction in productivity among SIC 382 producers. The implication is that manufacturers in the measuring and controlling devices sector located in oligopolistically organized regions suffer from a significant efficiency penalty.

[Table 5 near here]

In contrast, population density (DENSITY) registers an adverse effect on farm and garden machinery producers (of about 4 percent with each doubling of density) but not measuring and controlling devices manufacturers. Educational attainment $(A T T A I N)$ is significant for both sectors, though in opposite directions. In absolute terms, the magnitude of the effect is approximately equal. A ten percent increase in educational attainment is associated with a 1.3 percent reduction in productivity for SIC 352 but a 1.2 percent increase in productivity for SIC 382. Evaluating the impact on productivity of a change in the attainment rate in the context of the sample gives a better sense of the relative magnitude of the effect. The difference in the attainment rate between the first and third sample quartiles for SIC 352 is 22 percent. Assuming a constant elasticity with respect to attainment, that implies that farm and garden machinery plants at the third attainment quartile are 2.9 percent more productive than those at the first. This somewhat inexplicable result may reflect the attainment variable acting as a proxy for labor cost.

It would appear on the basis of the results thus far that farm and garden machinery manufacturers fare best in low density, peripheral locations where the workforce is moderate to low-skilled (and perhaps, therefore, commands a lower wage). The most efficient producers in the measuring and controlling devices industry, on the other hand, are located in competitively organized regions with higher levels of educational attainment. The findings are consistent with what we would expect of a high technology, knowledge-intensive industry that remains 
competitive by continuously innovating and a lower-technology industry producing more standardized products on a least cost basis.

Sources of external economies: SIC 352. Estimated output elasticities with respect to each spatial variable are reported in Table 6 for all four distance decay specifications. For farm and garden machinery, the results when the decay parameter is set to 0.75 indicate that the strongest efficiency effect is associated location in a region with the required mix of producer services. Doubling the producer services pool index increases output, other things equal, by 3.8 percent. The local availability of key services such as radio and television broadcasting, engineering, and advertising may allow manufacturers to out-source to a greater degree while also enjoying face-to-face contact with contractors. The output elasticity declines in magnitude and significance as the decay approaches a reciprocal form, falling to 0.016 when $\alpha=-50$ in equation (6). Consistent with the theory of urban hierarchies and central places, it would appear that productivity effects with respect to producer services are strongest at the broadest spatial scale.

Location in regions with high relative rates of innovation as measured by the patenting variable is also associated with greater efficiency among farm and garden machinery manufacturers. Output increases roughly 3.5 percent with each doubling of the patent rate, holding input levels constant. (Note that the definition of the patent variable does not include a distance decay.) Given the insignificant university R\&D elasticity, knowledge spillovers for this relatively low-tech manufacturing sector appear to be of more of an applied rather than basic nature; that is, if local patent grants may be taken as an indicator of information and knowledge creation in the form of immediately marketable goods and services.

[Table 6 near here] 
On the one hand, this interpretation should be viewed cautiously since university researchers do patent innovations and not all patents granted are of a purely applied nature. On the other hand, the purpose of patenting is to ensure that the pecuniary benefits of a particular innovation are appropriated by the inventor, at least directly and for some period. Basic research conducted by universities is not usually immediately marketable, although it may frequently generate marketable applications. Therefore, it may not be unreasonable to distinguish the patenting and university variables along an applied-to-basic research continuum. Of course, universities serve a number of different roles in given regions, from producing basic research (which may spin off new companies and product applications), to serving as a focal point for applied knowledge diffusion (witness industrial and agricultural extension housed in universities and colleges), to training the region's workforce.

Among the other proximity variables, the parameter on the specialized labor market variable is positive though not significant at conventional levels for all distance decays. The variable does increase in size and significance as the form of distance decay becomes steeper and closer to the reciprocal, suggesting that labor pooling effects may be relatively narrow in spatial extent.

The results with respect to proximity to supplies of manufactured inputs also vary according to the decay specification. Where $\alpha=0.75$, there is no productivity effect associated a high degree of potential supplier access. A farm and garden machinery plant's proximity to nominal producers of its key intermediate inputs does not appear to confer an efficiency premium, as is predicted by conventional agglomeration theory (as well as more recent contributions in industrial organization and economic geography). However, under increasingly severe distance decay profiles, the elasticity gradually increases in magnitude and significance, 
such that under a standard reciprocal decay, it appears to positively influence manufacturing efficiency. This might be taken to mean that only immediate proximity to sources of manufactured inputs improves efficiency. It may be the case that the increased use of just-intime (JIT) inventory and delivery systems, outsourcing, and other efficiency-improving flexible manufacturing regimes that require much tighter collaboration between purchasers and suppliers are most effective when the parties to the transactions are in very close spatial proximity. Such an interpretation would provide support for the industrial district model, at least with respect to a lower-tech machinery sector, since Marshallian theory explicitly emphasizes the limited areal size of a true "district." The interpretation is in contrast to the more traditional theory of industrial complexes, as well as the recent related literature on industrial clusters, where the spatial scale is often considered in very broad terms (metropolitan areas, multicounty regions, or even states).

Together with the evidence of urban diseconomies and educational attainment, the results suggest a regional spatial structure that confers the greatest spatial externality benefits to farm and garden machinery plants located in tight-knit industrial districts outside of high cost, high density urban cores. Strong regional producer services are advantageous, particularly if they can be secured from a low cost, possibly suburban location that also offers proximity to nearby like manufacturers and intermediate input suppliers. The finding is likely specific to this type of industry. We would expect to see very different patterns of spatial economies arising for higher technology industries that rely to a greater extent on R\&D and skilled labor (such as SIC 382) or natural resource industries that purchase few manufactured and non-manufactured inputs.

Sources of external economies: SIC 382. The influences of proximity are much more stable across alternative distance decay specifications for plants in the measuring and controlling 
devices sample. The strongest productivity premium is gained by location with ready access to producer services, though that access need not be immediately proximate to the firm. When $\alpha=0.75$ for the producer services index, a doubling of the index increases output by 1.9 percent, other things equal. As in the case of farm and garden machinery, the magnitude of the producer services effect declines as the decay profile steepens. Indeed, elasticity on the producer services pool is significant at conventional levels only when $\alpha=0.75$. That is further support, this time for a very different industry, for the notion that manufacturers' proximity to producer services is important at a primarily regional rather than local level; i.e. it is not necessary to be located immediately next door to services providers, but there is an advantage to locating in a region with a strong mix of key services.

In general, spatial externalities in SIC 382 appear to be more of the labor pooling variety. Plants located nearby industries that utilize similar labor are more efficient, other things equal. The magnitude of the effect, 0.013 , is remarkably stable across all four decay specifications. Proximity to sources of demand, on the other hand, appears to confer an efficiency penalty. As a group, the manufactured input pool, local demand pool, and labor market specialization variables measure different dimensions of industry localization. The labor variable measures specialization in related (similar labor using) industries in the plant's commuting shed. The input and demand pool variables measure proximity to producers in specific SIC 382 product chains. For producers in SIC 382, location in a broader region with a specialized industry mix is advantageous, but location close to demanders is actually costly. Also, while proximity to sources of supply appears to yield no productivity benefit, location nearby research universities does. The influence on efficiency of proximity to R\&D universities changes very little with alternative distance decays, declining only slightly as the decay becomes steeper, suggesting that 
spillovers from universities occur at a regional, rather than local, level. ${ }^{4}$

The coefficient on educational attainment together with the university R\&D elasticity reinforces a growing body of work on the key role of universities in urban and regional development. Estimating the impact of research universities on manufacturing productivity, or, for that matter, any measure of private sector performance, is extremely difficult. Universities influence local activities through several channels, i.e. the training of future workers, the production of basic research, the attraction of innovators and entrepreneurs who seek the amenities associated with university towns or communities, and the spin-off of new local firms seeking to capitalize on innovations developed inside the university. The findings reported here are stronger than others in capturing the specific knowledge-creating role of universities since the empirical model includes measures for multiple factors: educational attainment for the university's role in training, per capita patents for its role in attracting innovative residents and firms, and the university $\mathrm{R} \& \mathrm{D}$ index variable for knowledge input from universities to regional firms.

Although multiple interpretations are conceivable, one explanation for the general pattern of results for SIC 382 that is consistent with the high tech, labor quality dependent nature of the sector, is that the predominant spatial dynamic determining geographic productivity differentials in the industry is related to knowledge and information acquisition, and not necessarily efficient production scale (or the externalization of internal business functions). A specialized labor market with well-trained workers (see the coefficient on ATTAIN)-but also a competitively organized manufacturing region (CRATIO)-confers the greatest advantage, along with access to producer services and proximity to R\&D universities. Plants fare worse when located near their customers, possibly because of the ability of large producers to push many costs back to 
suppliers while also imposing inefficiencies (e.g., by requiring certain inflexible and customerspecific technological investments as a condition of contract). Proximity to local sources of demand exacts a lower penalty when the plant is located very close to demanders (modeled by the reciprocal decay) rather than at greater distances (modeled by the more gradual decays), suggesting that at very close proximity, the advantages of face-to-face interactions with demanders yield relative benefits that off-set the costs to a limited degree.

\section{Summary and Implications}

This paper develops and estimates a production function with several embedded indicators of commonly-hypothesized sources of business externalities, spillovers, and agglomeration economies. The indicators account for the rough distance between economic actors in a given plant's commuting or catchment shed (in some cases, region), as well as the unique production requirements of the study industries (manufactured input mix, producer services mix, and labor requirements mix). In order to estimate the function at the establishment level, all spatial variables are designed to be specific to each plant's location using distance-weighted countylevel data. The indicators are based on the Marshaillian theory of spatial external economies. In contrast to all previous production function studies of agglomeration, which assume homogeneity, if not linear homogeneity, at the outset, the translog system estimated here imposes no prior economic restrictions.

There are important similarities and differences and in the results for the two industries. For the lower technology farm and garden machinery industry, proximity to supplies of producer services and location in a region with relatively a high rate of innovation as proxied by per capita patent grants are consistently associated with higher levels of efficiency. That is, a plant located 
nearby the mix of services it requires, and/or in an innovative region, produces more output with a given vector of inputs than one located further away from producer services or where applied innovation rates are low. There is very little evidence that proximity to $R \& D$ universities influences productivity, perhaps implying that information spillovers in this comparatively standardized industry are related primarily to applied, rather than basic, research.

When the models are re-estimated using different distance decay specifications, some interesting findings emerge regarding the spatial scales at which specific types of proximity influence efficiency. Most significant is the increase in magnitude and significance of proximity to manufactured input supplies as the decay profile approaches the reciprocal. Since the reciprocal profile puts the most weight on immediate spatial proximity, supplier access yields a productivity benefit for producers in SIC 352 only at a very restricted spatial scale. That is, plants benefit from access to sources of supply as long as the suppliers are located in close proximity (i.e. within the same county). The labor pool variable also increases in magnitude and significance when other variables are defined under a more severe decay profile, though it never attains conventional significance levels. On the other hand, the productivity benefit of proximity to producer services appears strongest at the regional level, a finding that holds for the measuring and controlling devices sample as well. These results, coupled with the finding of diseconomies associated with urban density, suggest that for the average farm and garden machinery producer, the ideal location for maximizing spatial economies is in a specialized industrial district outside the dense urban core of an innovative region, but still within approximately one hour of higherorder producer services located in the core. In addition, there is no evidence that location in a region with an oligopolistic industry structure exacts a productivity penalty for firms in this industry. 
For the higher technology measuring and controlling devices sector, spatial economies are associated with access to producer services, a specialized labor market, and knowledge spillovers from university research. Plants are also more productive in regions with high rates of educational attainment (which suggests another avenue through which universities might influence firm performance) and less productive where local industry is less competitively structured. The latter supports Chinitz's (1961) view that the advantages of agglomeration may have as much to do with industry structure as with urban and industry scale. The rate of local innovation measured by patents and proximity to supplies of key inputs have no influence on efficiency, even under alternative decay profiles. In addition, there is evidence that proximity to sources of final market demand acts as a spatial diseconomy for measuring and controlling devices enterprises. That might be taken as support for the thesis in the business organization literature that suppliers that are closely tied to their OEM's may suffer a competitive disadvantage, as the OEM uses its market power and contracting decisions to push some costs back to suppliers, though the results are only suggestive in this regard. Finally, there is no evidence that plants in SIC 382 suffer from diseconomies associated with urban density, as was the case for producers in SIC 352.

Obviously the generalizability of the specific study results are limited in that only two industries are studied. However, the findings are highly suggestive of a very important point for agglomeration and externality research generally: the concepts of urbanization and localization, conceived in terms of scale alone and measured by urban and industry size indicators, do not represent distinct, much less mutually exclusive, phenomena. To the extent that the indicators used in this research are construct-valid measures of the underlying dimensions of local interfirm interaction, a comparison with traditional scale proxies shows that urbanization can represent the 
same dynamics for some industries that localization represents for others. Simple correlations of the proximity indicators with measures of urban and industry scale show that in the case of SIC 352, city size is most closely associated with proximity to intermediate inputs, producer services, universities and the level of innovation. Indeed, estimating traditional agglomeration economies for the two industries finds evidence of population scale (urbanization) economies in SIC 352 and industry scale (localization) economies in SIC 382 (see Feser 2001a). In the case of SIC 352, the population variable may be picking up, among other things, the productivity effect associated with access to input suppliers (traditionally viewed as a localization, not an urbanization, economy). Therefore, even if one distinguishes between urbanization and localization economies in empirical research, in the absence of additional information, it is not necessarily clear what those factors represent for a given industry. ${ }^{5}$

Finally, cities and states are now pursuing strategies to build industrial clusters where synergies associated with geographic proximity between firms are maximized (Roelandt and den Hertog, 1999; Porter, 2000). In a sense, business clusters represent a direct application of various theories of business externalities, spillovers, and agglomeration economies. The findings from this study suggest that cluster strategies aimed at leveraging externalities must be based on an empirical understanding of the kinds of inter-firm and inter-institutional proximity that matter most to businesses in different industries. Also, the results with respect to local industry structure suggest that cluster development strategies must be mindful of the overall impact of supplier consolidation occurring in many manufacturing sectors. Cluster strategies that, in effect, build a local industrial specialization are also influencing the industrial structure and possibly firm size distribution in a place. As Chinitz (1961) suggested, a regional cluster of one or more assembly plants with their major suppliers does not necessarily represent a competitive 
industrial mix that will enhance productivity and fuel entrepreneurship. Formal and informal linkages within the local cluster do not necessarily translate to growth outside the cluster, or to the development of other sectors. 


\section{References}

Acs, Z. J., D. B. Audretsch, and M. P. Feldman. 1992. Real effects of academic research: Comment. American Economic Review 82: 363-7.

Adams, J. D., and Jaffe, A. B. (1996) Bounding the Effects of R\&D: An Investigation Using Matched Establishment-Firm Data, Rand Journal of Economics, 27, 700-21.

Anselin, L., Varga, A., and Acs, Z. (1997) Local Geographic Spillovers Between University Research and High Technology Innovations, Journal of Urban Economics, 42, 422-48.

Beyers, W. B. (1992) Producer services and metropolitan growth and development in E. S. Mills and J. F. MacDonald (Eds.) Sources of Metropolitan Growth, pp. 125-46, New Jersey: Rutgers University Press.

Burt, D. N. (1989) Managing Suppliers up to Speed, Harvard Business Review, 67, 127-35.

Carlino, G. A. (1978) Economies of Scale in Manufacturing Location. Boston: Martinus Nijhoff Social Science Division.

Chinitz, B. (1961) Contrasts in Agglomeration: New York and Pittsburgh, American Economic Review, 51, 279-89.

Cooke, P., Boekholt, P., and Tödtling, F. (2000) The Governance of Innovation in Europe. London: Pinter.

Cooke, P., and Morgan, K. (1998) The Associational Economy. Oxford: Oxford University Press.

Doms, M. E. (1991) Essays on Capital Equipment and Energy Technology in the Manufacturing Sector, unpublished Ph.D. thesis, University of Wisconsin at Madison.

Enright, M. J. (1995) Organization and coordination in geographically concentrated industries, in N. R. Lamoreaux and D. M. G. Raff (Eds.) Coordination and Information: Historical 
Perspectives on the Organization of Enterprise, pp. 103-142, Chicago: University of Chicago Press.

Evans, A. W. (1972) the Pure Theory of City Size in an Industrial Economy, Urban Studies, 9, 49-78.

Feser, E. J. (1998) Enterprise, External Economies, and Economic Development, Journal of Planning Literature, 12, 283-302.

Feser, E. J. (2001a) a Flexible Test for Agglomeration Economies in Two U.S. Manufacturing Industries, Regional Science and Urban Economics, 31, 1-19.

Feser, E. J. (2001b) Agglomeration, enterprise size, and productivity, in B. Johansson, C. Karlsson, and R. R. Stough (Eds.) Theories of Endogenous Regional Growth, pp. 231-51. Berlin: Springer.

Glaeser, E. L., Kallal, H. D., Scheinkman, J. A., and Shleifer, A. (1992) Growth in Cities, Journal of Political Economy, 100, 1126-1152.

Goe, W. R. (1991) the Growth of Producer Services Industries: Sorting Through the Externalization Debate, Growth and Change, 22, 118-41.

Griliches, Z. (1990) Patent Statistics as Economic Indicators: a Survey, Journal of Economic Literature, 28, 1661-1707.

Helper, S. 1991. Strategy and Irreversibility in Supplier Relations: the Case of the U.s. Automobile Industry, Business History Review, 65, 781-824.

Henderson, J. V. (1986) Efficiency of Resource Usage and City Size, Journal of Urban Economics, 19, 47-70.

Hoover, E. M. (1937) Location Theory and the Shoe and Leather Industries, Cambridge, MA: Harvard University Press.

Imrie, R. and Morris, J. (1992) a Review of Recent Changes in Buyer-supplier Relations, Omega 
20, 641-52.

Isard, W. (1956) Location and Space Economy, New York: John Wiley.

Jaffe, A. B. (1989) Real Effects of Academic Research, American Economic Review, 79, 957-70.

Jaffe, A. B., Trajtenberg, M., and Henderson, R. (1993) Geographic Localization of Knowledge Spillovers as Evidenced by Patent Citations, Quarterly Journal of Economics, 108, 57798.

Kim, H. Y. (1992) the Translog Production Function and Variable Returns to Scale, Review of Economics and Statistics, 74, 546-51.

Klier, T. H. (1994) the Impact of Lean Manufacturing on Sourcing Relationships, Economic Perspectives, July/August, 8-18.

Krugman, P. (1991) Geography and Trade, Cambridge: MIT Press.

Lucas, R. E., Jr. (1988) on the Mechanics of Economic Development, Journal of Monetary Economics, 22, 3-42.

Marshall, A. (1961) Principles of Economics: An Introductory Volume, $9^{\text {th }}$ ed. ( $1^{\text {st }}$ ed., 1890), London: Macmillan.

Moomaw, R. L. (1983) Spatial Productivity Variations in Manufacturing: a Critical Survey of Cross-sectional Analysis, International Regional Science Review, 8, 1-22.

Moomaw, R. L. (1988) Agglomeration Economies: Localization or Urbanization?, Urban Studies, 25, 150-61.

Moomaw, R. L. (1998) Agglomeration Economies: Are They Exaggerated by Industrial Aggregation?, Regional Science and Urban Economics, 28, 199-211.

Nakamura, R. (1985) Agglomeration Economies in Urban Manufacturing Industries, a Case of Japanese Cities, Journal of Urban Economics, 17, 108-24.

Newman, R. G. (1989) Single Sourcing: Short-term Savings Versus Long-term Problems, 
Journal of Purchasing and Materials Management, 25, 20-25.

Norton, R. D. (2000) the Geography of the New Economy, in S. Loveridge (Ed.) Web Book in Regional Science. www.rri.wvu.edu/webbook/norton.

Porter, M. (2000) Location, Competition, and Economic Development: Local Clusters in a Global Economy, Economic Development Quarterly, 14, 15-34.

Richardson, H. W. (1974) Agglomeration Potential: a Generalization of the Income Potential Concept, Journal of Regional Science, 14, 325-36.

Robinson, E. A. G. (1931) The Structure of Competitive Industry, Cambridge: Cambridge University Press.

Roelandt, T., and den Hertog, P. (1999) Boosting Innovation: The Cluster Approach, Organisation for Economic Co-operation and Development, Paris.

Romer, P. M. (1986) Increasing Returns and Long-run Growth, Journal of Political Economy, 94, 1002-37.

Sasaki, K. (1985) Regional Difference in Total Factor Productivity and Spatial Features, Regional Science and Urban Economics, 15, 489-516.

Saxenian, A. (1994) Regional Advantage: Culture and Competition in Silicon Valley and Route 128, Cambridge, MA: Harvard University Press.

Scott, A. J. (1986) Industrial Organization and Location: Division of Labor, the Firm, and Spatial Process, Economic Geography, 63, 215-31.

Stigler, G. J. (1951) the Division of Labour Is Limited by the Extent of the Market, Journal of Political Economy, 59, 185-93.

Weber, A. (1929) Theory of the Location of Industries, C. J. Friedrich (Trans.), Chicago: University of Chicago Press.

Zucker, L. G., Darby, M. R., and Armstrong, J. (1998) Geographically Localized Knowledge: 
Spillovers or Markets?, Economic Inquiry, 36, 65-86. 


\section{APPENDIX}

This appendix describes the construction of measures of the conventional factors and cost shares of the production function for each sector. Unless otherwise noted, all data are from the Longitudinal Research Database of the U.S. Census.

Output. Output at plant $i, Y_{i}$, is defined as the total value of shipments adjusted for inventories and work in process:

$$
\mathrm{Y}_{\mathrm{i}}=T V S_{i}+\left(W I E_{i}-W I B_{i}\right)+\left(F I E_{i}-F I B_{i}\right)
$$

where $T V S_{i}$ is the total value of shipments, WIE $E_{i}$ is work in process at the end of the year, WIB is work in process at the beginning of the year, $F I E_{i}$ is the end-year value of finished product inventories, and $F I B_{i}$ is the value of finished product inventories at the beginning of the year.

Capital. Capital services input is defined as the sum of the book values of capital assets and capitalized rentals:

$$
\mathrm{K}_{\mathrm{i}}=\left(B A E_{i}+M A E_{i}\right)+\left(C B R_{i}+C M R_{i}\right)
$$

where $B A E_{i}$ is the value of building assets at the end of the year, $M A E_{i}$ is the value of machinery assets at the end of the year, and $C B R_{i}$ and $C M R_{i}$ are capitalized building and machinery rentals. The latter are derived by dividing rental expenditures for each asset category by two-digit SIC capital prices from the Bureau of Labor Statistics. Defining capital services in terms of gross stocks, or the sum of building and machinery assets, has been demonstrated by Doms (1991) to represent a reasonable approximation in micro-level research using the LRD.

Labor. In addition to the number and total wages of production and nonproduction workers, the U.S. Census of Manufactures provides data on the total number of hours worked by 
production employees in the given year. If the average hourly wage of production workers at plant $i, P_{l p i}$, is the ratio of total production wage payments to hours, an estimate of total worker hours may be derived as:

$$
L_{i}=\left(W_{p i}+W_{n i}\right) / P_{l p i}
$$

where $W_{p i}$ and $W_{n i}$ are production and nonproduction worker wages and salaries, respectively.

Energy. LRD data were used along with energy cost and price information from the Energy Information Administration's most recent State Energy Price and Expenditure Report (SEPER) to develop the following plant-specific quantity measure of energy usage:

$$
E_{i s}=E Y_{j}+\sum_{g} \frac{C F_{j}\left(C F_{g s} / T C_{s}\right)}{P_{g s}}, \quad T C_{s}=\sum_{g} C_{g s}
$$

where $E_{i s}$ is total energy usage in British thermal units (Btu) by plant $i$ in state $s, E Y_{i}$ is electricity consumption (Btu) by plant $i, C F_{i}$ total fuel expenditures by plant $i, C F_{g s}$ is total expenditures for fuel $g$ ( $g=$ coal, natural gas, petroleum) by the industrial sector in state $s$, and $P_{g s}$ is the per Btu average price of fuel $g$ in state $s$.

Materials. Given $E_{i s}$, materials input for plant $i, M_{i}$, is simply the sum of expenditures for materials and contract work.

Costs. Capital costs consist of rental expenditures for buildings and machinery as reported directly in the LRD and expenditures for building and machinery assets. The latter are derived by multiplying reported end-of-year assets by unpublished BLS structures and equipment rental prices for SICs 35 and 38. Total labor costs are the sum of salaries, wages, and voluntary and required supplemental labor costs. Energy costs are the sum of fuels and electricity expenditures. The total cost of production is the sum of capital, labor, material and energy expenditures. 


$$
\begin{aligned}
\ln Y_{(S I C 352)}= & \alpha_{0}+\alpha_{k} \ln K+\alpha_{l} \ln L+\alpha_{e} \ln E+\alpha_{m} \ln M+\zeta \ln D E N S I T Y+\kappa \ln A T T A I N+ \\
& \frac{1}{2} \beta_{k k}(\ln K)^{2}+\beta_{k l} \ln K \ln L+\beta_{k e} \ln K \ln E+\beta_{k m} \ln K \ln M+\frac{1}{2} \beta_{l l}(\ln L)^{2}+ \\
& \beta_{l e} \ln L \ln E+\beta_{l m} \ln L \ln M+\frac{1}{2} \beta_{e e}(\ln E)^{2}+\beta_{e m} \ln E \ln M+\frac{1}{2} \beta_{m m}(\ln M)^{2}+ \\
& \xi_{t} \ln A_{t}+\xi_{s} \ln A_{s}+\gamma_{k s} \ln K \ln A_{s}+\gamma_{l s} \ln L \ln A_{s}+\gamma_{e s} \ln E \ln A_{s}+ \\
& \gamma_{m s} \ln M \ln A_{s}+\xi_{r} \ln A_{r}+\xi_{u} \ln A_{u}+\xi_{p} \ln A_{p}+\gamma_{k p} \ln K \ln A_{p}+\gamma_{l p} \ln L \ln A_{p}+ \\
& \gamma_{e p} \ln E \ln A_{p}+\gamma_{m p} \ln M \ln A_{p}+\varepsilon
\end{aligned}
$$

$$
\begin{aligned}
\ln Y_{(S I C 352)}= & \alpha_{0}+\alpha_{k} \ln K+\alpha_{l} \ln L+\alpha_{e} \ln E+\alpha_{m} \ln M+\zeta \ln D E N S I T Y+\kappa \ln A T T A I N+ \\
& \frac{1}{2} \beta_{k k}(\ln K)^{2}+\beta_{k l} \ln K \ln L+\beta_{k e} \ln K \ln E+\beta_{k m} \ln K \ln M+\frac{1}{2} \beta_{l l}(\ln L)^{2}+ \\
& \beta_{l e} \ln L \ln E+\beta_{l m} \ln L \ln M+\frac{1}{2} \beta_{e e}(\ln E)^{2}+\beta_{e m} \ln E \ln M+\frac{1}{2} \beta_{m m}(\ln M)^{2}+ \\
& \xi_{t} \ln A_{t}+\xi_{s} \ln A_{s}+\xi_{r} \ln A_{r}+\gamma_{k r} \ln K \ln A_{r}+\gamma_{l r} \ln L \ln A_{r}+\gamma_{e r} \ln E \ln A_{r}+ \\
& \gamma_{m r} \ln M \ln A_{r}++\xi_{u} \ln A_{u}+\gamma_{k u} \ln K \ln A_{u}+\gamma_{l u} \ln L \ln A_{u}+\gamma_{e u} \ln E \ln A_{u}+ \\
& \gamma_{m u} \ln M \ln A_{u}+\xi_{p} \ln A_{p}+\gamma_{k p} \ln K \ln A_{p}+\gamma_{l p} \ln L \ln A_{p}+\gamma_{e p} \ln E \ln A_{p}+ \\
& \gamma_{m p} \ln M \ln A_{p}+\xi_{d} \ln A_{d}+\varepsilon
\end{aligned}
$$

Final estimated equations. The final estimated production functions are written as:

Fig. 1 Distance decay profiles

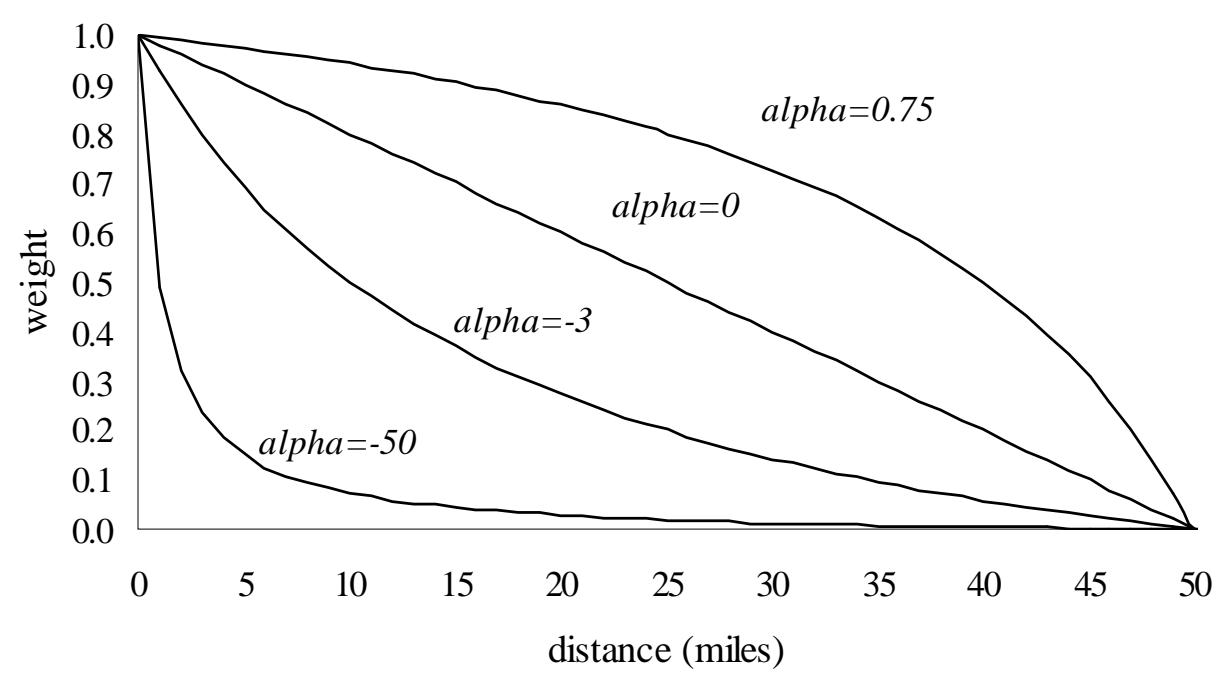




\begin{tabular}{|c|c|c|c|c|c|}
\hline \multicolumn{6}{|c|}{$\begin{array}{c}\text { Table } 1 \\
\text { Descriptive statistics, study industries, } 1992\end{array}$} \\
\hline \multirow[b]{2}{*}{ Variable } & \multirow[b]{2}{*}{ Description } & \multicolumn{2}{|c|}{$\operatorname{SIC} 352(n=863)$} & \multicolumn{2}{|c|}{$\operatorname{SIC} 382(n=2,609)$} \\
\hline & & Mean & Std. Dev. & Mean & Std. Dev \\
\hline $\mathrm{Y}$ & Output (000s) & 16,667 & 74,559 & 12,553 & 36,314 \\
\hline $\mathrm{K}$ & Capital (000s) & $5,820.6$ & $31,992.4$ & $4,716.5$ & $17,306.8$ \\
\hline $\mathrm{L}$ & Labor (000s Manhours) & 215.7 & 575.6 & 275.5 & 723.8 \\
\hline $\mathrm{E}$ & Energy (Million Btus) & 16,882 & 79,943 & 8,494 & 26,368 \\
\hline M & Materials (000s) & $7,773.8$ & $32,946.7$ & $4,160.4$ & $12,829.7$ \\
\hline $\mathrm{S}_{\mathrm{k}}$ & Capital cost share & .0492 & .0246 & .0955 & .0567 \\
\hline$S_{1}$ & Labor cost share & .3882 & .1244 & .4938 & .1271 \\
\hline $\mathrm{S}_{\mathrm{e}}$ & Energy cost share & .0148 & .0116 & .0124 & .0106 \\
\hline $\mathrm{S}_{\mathrm{m}}$ & Material cost share & .5478 & .1355 & .3983 & .1400 \\
\hline$A_{t}$ & Local material pool & 455 & 806 & 3,128 & 2,775 \\
\hline $\mathrm{A}_{\mathrm{s}}$ & Local service pool & 2,620 & 5,808 & 15,876 & 16,953 \\
\hline$A_{r}$ & Specialized labor pool & 25.8 & 15.2 & 7.3 & 5.8 \\
\hline$A_{d}$ & Local demand pool & ------ & ----- & 2,659 & 3,916 \\
\hline $\mathrm{A}_{\mathrm{u}}$ & University R\&D & 7,910 & 15,501 & 60,416 & 68,200 \\
\hline$A_{p}$ & Local patent rate & 15.1 & 11.6 & 26.8 & 12.0 \\
\hline CRATIO & Industry structure/concentration & .4515 & .2181 & .2663 & .1567 \\
\hline ATTAIN & Educational attainment & .1747 & .0448 & .2338 & .0485 \\
\hline DENSITY & Population density & 190 & 359 & 850 & 791 \\
\hline
\end{tabular}

\begin{tabular}{|c|c|c|c|c|c|c|}
\hline \multicolumn{7}{|c|}{$\begin{array}{c}\text { Table } 2 \\
\text { Pairwise correlations, proximity variables }\end{array}$} \\
\hline Variable & $A_{t}$ & $\mathrm{~A}_{\mathrm{s}}$ & $A_{r}$ & $\mathrm{~A}_{\mathrm{u}}$ & $A_{p}$ & $\mathrm{~A}_{\mathrm{d}}$ \\
\hline \multicolumn{7}{|c|}{ Farm and garden machinery (SIC 352) } \\
\hline $\begin{array}{l}\mathrm{A}_{\mathrm{T}} \text { (Materials) } \\
\mathrm{A}_{\mathrm{S}} \text { (Services) } \\
\mathrm{A}_{\mathrm{R}} \text { (Labor) } \\
\mathrm{A}_{\mathrm{U}} \text { (Universities) } \\
\mathrm{A}_{\mathrm{P}} \text { (Patents) }\end{array}$ & $\begin{array}{l}1.000 \\
.7030 \\
.0462 \\
.2175 \\
.4513\end{array}$ & $\begin{array}{r}1.000 \\
-.1013 \\
.3144 \\
.3078\end{array}$ & $\begin{array}{r}1.000 \\
-.0039 \\
.0557\end{array}$ & $\begin{array}{l}1.000 \\
.2775\end{array}$ & 1.000 & \\
\hline \multicolumn{7}{|c|}{ Measuring and controlling devices (SIC 382) } \\
\hline $\begin{array}{l}A_{t} \\
A_{s} \\
A_{r} \\
A_{u} \\
A_{p} \\
A_{d} \text { (Demand) }\end{array}$ & $\begin{array}{l}1.000 \\
.5996 \\
.3476 \\
.5246 \\
.4324 \\
.5658\end{array}$ & $\begin{array}{l}1.000 \\
.2422 \\
.3464 \\
.0189 \\
.6033\end{array}$ & $\begin{array}{l}1.000 \\
.4365 \\
.2195 \\
.4079\end{array}$ & $\begin{array}{l}1.000 \\
.2544 \\
.3366\end{array}$ & $\begin{array}{r}1.000 \\
-.0230\end{array}$ & 1.000 \\
\hline
\end{tabular}


Table 3

Pairwise Correlations: Externality Factors and Traditional Agglomeration Measures: SIC 352 and 382

\begin{tabular}{|l|r|r|r|r|}
\hline & \multicolumn{2}{|c|}{ SIC 352 } & \multicolumn{2}{c|}{ SIC 382 } \\
\hline Externality & & $\begin{array}{c}\text { Industry } \\
\text { Enployment }\end{array}$ & Population & $\begin{array}{c}\text { Industry } \\
\text { Employment }\end{array}$ \\
\hline Indicator & Population & Employm & .6474 & .8221 \\
$\mathrm{~A}_{\mathrm{t}}$ (Materials) & .7411 & .2442 & .6474 \\
$\mathrm{~A}_{\mathrm{s}}$ (Services) & .9407 & -.0138 & .9490 & .5665 \\
$\mathrm{~A}_{\mathrm{r}}$ (Labor) & -.1052 & .2869 & .2596 & .3797 \\
$\mathrm{~A}_{\mathrm{u}}$ (Universities) & .3066 & .0228 & .3688 & .6073 \\
$\mathrm{~A}_{\mathrm{p}}$ (Patents) & .3843 & .2078 & .0677 & .4663 \\
$\mathrm{~A}_{\mathrm{d}}$ (Demand) & ------ & ------ & .5939 & .4006 \\
\hline
\end{tabular}

Table 4

Likelihood ratio statistics, tests on model restrictions

\begin{tabular}{|l|c|c|c|c|}
\hline & SIC 352 & SIC 382 & $95 \%$ critical value & $99 \%$ critical value \\
\hline Technology assumptions & & & & \\
Technology cross terms & 3.20 & 6.95 & $25.00 / 32.67$ & $30.58 / 38.93$ \\
Homotheticity & 7.25 & 9.11 & 9.49 & 13.28 \\
Homogeneity & 1.36 & 2.03 & $5.99 / 7.82$ & $9.21 / 11.34$ \\
Linear homogeneity & 0.72 & 6.24 & 3.84 & 6.63 \\
Hicks-Neutrality & & & & \\
Manufactured input & 1.06 & 2.93 & 9.49 & 13.28 \\
pool & 5.72 & 1.39 & 9.49 & 13.28 \\
Producer services pool & 1.33 & 19.65 & 9.49 & 13.28 \\
Specialized labor pool & ---- & 0.45 & 9.49 & 13.28 \\
Local demand pool & 1.50 & 7.05 & 9.49 & 37.28 \\
Research universities & 3.24 & 4.89 & 9.49 & \\
Local innovation rate & 20.78 & 61.09 & $31.41 / 36.42$ & \\
All spatial economies & & & & \\
\hline
\end{tabular}

Note: Hicks-neutrality tests are conducted for non-homothetic model. Critical value on left side of forward slash applies to SIC 352. 


\begin{tabular}{|c|c|c|c|c|c|c|}
\hline \multicolumn{7}{|c|}{$\begin{array}{c}\text { Table } 5 \\
\text { Parameter estimates and asymptotic standard errors }\end{array}$} \\
\hline & \multicolumn{3}{|c|}{ SIC 352} & \multicolumn{3}{|c|}{ SIC 382} \\
\hline Parameter & Estimate & s.e. & t-stat & Estimate & s.e. & t-stat \\
\hline$\alpha_{0}$ & 1.9544 & 0.1878 & 10.41 & 2.7445 & 0.0914 & 30.04 \\
\hline$\alpha_{k}$ & 0.0246 & 0.0025 & 9.81 & 0.0285 & 0.0037 & 7.64 \\
\hline$\alpha_{1}$ & 0.8614 & 0.0129 & 66.58 & 0.8529 & 0.0100 & 85.48 \\
\hline$\alpha_{\mathrm{m}}$ & 0.1530 & 0.0171 & 8.98 & 0.1388 & 0.0079 & 17.60 \\
\hline$\alpha_{\mathrm{e}}$ & -0.0074 & 0.0019 & -3.96 & -0.0016 & 0.0012 & -1.26 \\
\hline CRATIO & & & & -0.1309 & 0.0468 & -2.80 \\
\hline ATTAIN & -0.1302 & 0.0641 & -2.03 & 0.1197 & 0.0344 & 3.48 \\
\hline DENSITY & -0.0438 & 0.0228 & -1.92 & & & \\
\hline$\beta_{\mathrm{kk}}$ & 0.0404 & 0.0006 & 67.31 & 0.0755 & 0.0007 & 102.48 \\
\hline$\beta_{\mathrm{kl}}$ & -0.0118 & 0.0006 & -19.19 & -0.0347 & 0.0008 & -42.61 \\
\hline$\beta_{\mathrm{km}}$ & -0.0287 & 0.0006 & -49.73 & -0.0411 & 0.0007 & -63.22 \\
\hline$\beta_{\mathrm{ke}}$ & 0.0001 & 0.0003 & 0.19 & 0.0003 & 0.0002 & 1.46 \\
\hline$\beta_{\mathrm{ll}}$ & 0.1765 & 0.0034 & 52.62 & 0.1714 & 0.0020 & 86.58 \\
\hline$\beta_{\mathrm{lm}}$ & -0.1622 & 0.0030 & -53.80 & -0.1324 & 0.0016 & -84.67 \\
\hline$\beta_{\mathrm{le}}$ & -0.0025 & 0.0005 & -5.25 & -0.0043 & 0.0003 & -15.55 \\
\hline$\beta_{\mathrm{ee}}$ & 0.0116 & 0.0004 & 32.40 & 0.0087 & 0.0002 & 39.90 \\
\hline$\beta_{\mathrm{em}}$ & -0.0092 & 0.0004 & -21.41 & -0.0047 & 0.0002 & -20.30 \\
\hline$\beta_{\mathrm{mm}}$ & 0.2000 & 0.0029 & 69.44 & 0.1782 & 0.0015 & 118.05 \\
\hline$\xi_{\mathrm{t}}$ & 0.0005 & 0.0096 & 0.05 & -0.0056 & 0.0114 & -0.49 \\
\hline$\xi_{\mathrm{s}}$ & 0.0589 & 0.0288 & 2.05 & 0.0188 & 0.0100 & 1.88 \\
\hline$\gamma_{\mathrm{ks}}$ & -0.0002 & 0.0003 & -0.58 & & & \\
\hline$\gamma_{\mathrm{ls}}$ & 0.0003 & 0.0005 & 0.64 & & & \\
\hline$\gamma_{\mathrm{es}}$ & 0.0011 & 0.0002 & 4.74 & & & \\
\hline$\gamma_{\mathrm{ms}}$ & -0.0042 & 0.0025 & -1.66 & & & \\
\hline$\xi_{\mathrm{u}}$ & 0.0000 & 0.0019 & -0.02 & 0.0107 & 0.0032 & 3.33 \\
\hline$\gamma_{\mathrm{ku}}$ & & & & -0.0001 & 0.0002 & -0.45 \\
\hline$\gamma_{\text {lu }}$ & & & & 0.0014 & 0.0005 & 2.86 \\
\hline$\gamma_{\mathrm{eu}}$ & & & & -0.0002 & 0.0001 & -3.31 \\
\hline$\gamma_{\mathrm{mu}}$ & & & & -0.0011 & 0.0004 & -2.79 \\
\hline$\xi_{\mathrm{p}}$ & 0.0766 & 0.0208 & 3.69 & 0.0231 & 0.0196 & 1.18 \\
\hline$\gamma_{\mathrm{kp}}$ & -0.0011 & 0.0005 & -2.08 & -0.0040 & 0.0012 & -3.33 \\
\hline$\gamma_{l p}$ & 0.0140 & 0.0032 & 4.37 & 0.0119 & 0.0031 & 3.78 \\
\hline$\gamma_{\mathrm{ep}}$ & -0.0012 & 0.0004 & -2.87 & -0.0007 & 0.0004 & -1.81 \\
\hline$\gamma_{\mathrm{mp}}$ & -0.0117 & 0.0029 & -3.97 & -0.0072 & 0.0026 & -2.80 \\
\hline$\xi_{\mathrm{r}}$ & 0.0133 & 0.0154 & 0.86 & 0.0293 & 0.0089 & 3.30 \\
\hline$\gamma_{\mathrm{kr}}$ & & & & -0.0009 & 0.0006 & -1.55 \\
\hline$\gamma_{\mathrm{lr}}$ & & & & 0.0073 & 0.0015 & 4.97 \\
\hline$\gamma_{\mathrm{er}}$ & & & & 0.0013 & 0.0002 & 7.15 \\
\hline$\gamma_{\mathrm{mr}}$ & & & & -0.0077 & 0.0012 & -6.38 \\
\hline$\xi_{\mathrm{d}}$ & & & & -0.0232 & 0.0084 & -2.75 \\
\hline$\theta$ & 1.0115 & 0.0060 & 167.66 & 1.0187 & 0.0038 & 271.66 \\
\hline $\mathrm{N}$ & & 863 & & & 2,609 & \\
\hline Adj. $R^{2 \prime s}$ & Output & 0.968 & & & 0.957 & \\
\hline & $\mathrm{K}$ share & 0.837 & & & 0.780 & \\
\hline & L share & 0.710 & & & 0.690 & \\
\hline & M share & 0.798 & & & 0.828 & \\
\hline
\end{tabular}




\begin{tabular}{|c|c|c|c|c|c|c|}
\hline \multicolumn{7}{|c|}{$\begin{array}{c}\text { Table } 6 \\
\text { Output elasticities with respect to proximity, varying distance decays } \\
\text { Parameter estimates and asymptotic standard errors }\end{array}$} \\
\hline & \multicolumn{3}{|c|}{ SIC 352} & \multicolumn{3}{|c|}{ SIC 382} \\
\hline & Estimate & $\begin{array}{l}\text { Std. } \\
\text { Error }\end{array}$ & t-stat & Estimate & $\begin{array}{l}\text { Std. } \\
\text { Error }\end{array}$ & t-Stat \\
\hline & \multicolumn{6}{|c|}{ Alpha $=0.75$ (Initial Assumption) } \\
\hline Manufactured input pool & 0.000 & 0.010 & 0.05 & -0.006 & 0.011 & -0.49 \\
\hline Producer services pool & 0.038 & 0.020 & 1.89 & 0.019 & 0.010 & 1.88 \\
\hline Specialized labor pool & 0.013 & 0.015 & 0.86 & 0.013 & 0.007 & 1.86 \\
\hline Local demand pool & & & & -0.023 & 0.008 & -2.75 \\
\hline Research universities & 0.000 & 0.002 & -0.02 & 0.007 & 0.003 & 2.78 \\
\hline \multirow[t]{2}{*}{ Local innovation rate } & 0.035 & 0.016 & 2.20 & -0.006 & 0.015 & -0.38 \\
\hline & \multicolumn{6}{|c|}{ Alpha $=0$ (Linear $)$} \\
\hline Manufactured input pool & 0.005 & 0.009 & 0.52 & -0.007 & 0.010 & -0.68 \\
\hline Producer services pool & 0.037 & 0.016 & 2.35 & 0.015 & 0.009 & 1.58 \\
\hline Specialized labor pool & 0.015 & 0.015 & 0.96 & 0.013 & 0.007 & 1.89 \\
\hline Local demand pool & & & & -0.020 & 0.008 & -2.50 \\
\hline Research universities & 0.000 & 0.002 & 0.12 & 0.007 & 0.002 & 2.84 \\
\hline \multirow[t]{2}{*}{ Local innovation rate } & 0.035 & 0.016 & 2.19 & -0.004 & 0.015 & -0.24 \\
\hline & \multicolumn{6}{|c|}{ Alpha $=-3.0$} \\
\hline Manufactured input pool & 0.010 & 0.009 & 1.22 & -0.005 & 0.010 & -0.49 \\
\hline Producer services pool & 0.030 & 0.012 & 2.39 & 0.014 & 0.009 & 1.54 \\
\hline Specialized labor pool & 0.016 & 0.015 & 1.08 & 0.013 & 0.007 & 1.97 \\
\hline Local demand pool & & & & -0.020 & 0.008 & -2.44 \\
\hline Research universities & 0.001 & 0.002 & 0.35 & 0.006 & 0.002 & 2.92 \\
\hline \multirow[t]{2}{*}{ Local innovation rate } & 0.035 & 0.016 & 2.21 & -0.006 & 0.015 & -0.40 \\
\hline & \multicolumn{6}{|c|}{ Alpha $=-50.0$ (Reciprocal) } \\
\hline Manufactured input pool & 0.015 & 0.007 & 2.14 & -0.005 & 0.008 & -0.55 \\
\hline Producer services pool & 0.016 & 0.009 & 1.73 & 0.008 & 0.008 & 1.01 \\
\hline Specialized labor pool & 0.017 & 0.015 & 1.13 & 0.013 & 0.007 & 1.84 \\
\hline Local demand pool & & & & -0.014 & 0.007 & -1.85 \\
\hline Research universities & 0.001 & 0.002 & 0.74 & 0.005 & 0.002 & 2.91 \\
\hline Local innovation rate & 0.035 & 0.016 & 2.22 & -0.006 & 0.014 & -0.43 \\
\hline
\end{tabular}

Note: Revised models with homogeneitv imposed. 
1. The research in this paper was conducted while the author was a research associate at the Center for Economic Studies, U.S. Bureau of the Census. Research results and conclusions expressed are those of the author and do not necessarily indicate concurrence by the Bureau of the Census or the Center for Economic Studies. Special thanks to two anonymous reviewer for suggestions that substantially improved the paper.

2. The survey covers institutions that grant doctorates in the sciences or engineering and/or annually perform at least $\$ 50,000$ in separately budgeted $R \& D$. In 1993 , a full population (or census) survey year, 628 institutions reported R\&D expenditures for a wide variety of specific disciplines.

3. All parameter estimates from each stage are available from the author upon request.

4. To test the extent of the regional effect, a university $R \& D$ variable defined for a 250 mile catchment shed was tested. The variable was consistently insignificant for both sectors, suggesting that the spillover effect of the university is a local one in terms of direct influence on manufacturing performance. Of course, universities also contribute trained labor and nonlocal or "mobile" knowledge spillovers that may exert a very broad spatialand not necessarily continuous-impact.

5. Effects may also differ significantly for producers of different sizes. Estimations of this study's models for establishments in different size categories are reported in Feser (2001b). 